\title{
Evaluation of Craniocerebral Trauma Using Computed Tomography
}

\author{
Satish Prasad B.S ${ }^{1}$, Shama M Shetty ${ }^{2}$ \\ 1. Professor and HOD, Department of Radiodiagnosis, Adichunchangiri Institute Of Medical Sciences \\ ,Karnataka \\ 2. Junior Resident, Department of Radiodiagnosis, Adichunchangiri Institute Of Medical Sciences, Karnataka
}

\begin{abstract}
:
Aims And Objective: Objective of the present study is to evaluate and assess the role of computed tomography in patients with craniocerebral trauma in respect to:

$>$ study the different traumatic lesions in trauma to the head

$>\quad$ to establish that CT has a significant role in management of patients with head injury

$>$ to assess the prognostic significance of CT in outcome of patients of head injury.

Methods:This is a prospective analysis of 100 patients with craniocerebral trauma using computed tomography who were treated at our institution from Nov 2009 to Oct 2011. Findings of the computed tomography using Helical CT scanner, GE CT machine were computed and compiled.

Result: The results of the study revealed that the incidence of craniocerebral trauma was more in male population. The peak incidence of age was found in the age group of 18-30 years. Although fractures and contusions constituted about $84.6 \%$ and $57 \%$ respectively, subdural hematoma was commonest cause of morbidity and mortality in craniocerebral trauma forming about $32.1 \%$ followed by extradural hematomas $12.5 \%$

Conclusion: Computed Tomography is one of the comprehensive diagnostic modality for accurate localisation of the site of injury in acute craniocerebral trauma. The early and timely diagnosis of the precise lesion by CT not only had substantial impact over instituting appropriate treatment and timely surgical intervention but also helped in predicting the ultimate outcome.
\end{abstract}

Key Words: Craniocerebral trauma, Computed Tomography, Fractures, Epidural Hematomas, Subdural Hematomas, Contusions

\section{Introduction:}

In a rapidly developing country like India, road transportation is massively increasing due to urbanisation and industrialization. As a result, head injuries due to road traffic accidents have become a daily occurrence taking an increased toll on human lives and limbs. Most of these patients are in their prime $\left(2^{\text {nd }}\right.$ and $3^{\text {rd }}$ decade ) and therefore have a direct social and economic effect besides the emotional burden of suffering a lifelong debilitating loss of function.

The primary goal in treating patients with craniocerebral trauma due to any cause is to preserve the patient's life and remaining neurological function. Optimal management of these patients depends on early and correct diagnosis and therefore neuroimaging has a vital role. The advent of CT has been a major breakthrough as it meets these vital requirements. CT also forms the principle screening modality for victims of both blunt and traumatic injuries.

CT is the single most informative modality in the evaluation of patients with head injury. Besides facilitating rapid implementation, it can demonstrate significant primary traumatic injuries including extradural, subdural, intracerebral hematomas, subarachnoid and intra ventricular haemorrhages, skull fractures, cerebral oedema, contusions and cerebral herniations. Prompt recognition of treatable injuries is critical to reduce mortality and $\mathrm{CT}$ of the head is the cornerstone for rapid diagnosis ${ }^{10}$.

$\mathrm{CT}$ is currently the procedure of choice over MRI because it is faster and more readily available. $\mathrm{CT}$ is quick, cost effective, non-invasive method to assess the time and extent of cerebral injury and is an essential aid to triage patients to observation, medical or surgical management. This study attempts to assess the utility of CT in the diagnosis, management and prognosis of patients with cerebral trauma.

\section{Materials And Methods:}

Study Design: This is a prospective study carried out in patients of head injury, referred to the department of Radiodiagnosis ,Sri Adichunchanagiri Hospital and Research Centre, B.G. Nagara, Nagamangala Taluk, Mandya District from Nov 2009 to Oct 2011. A total of 100 patients with a history of road traffic accident, fall or assault were included and analysed in the study. 


\section{Inclusion Criteria:}

1) Adults from the age of 18 years onwards

2) Patients with a history of road traffic accident, fall or assault were included in this study.

\section{Exclusion Criteia:}

1) Pediatric cases

2) Penetrating injuries

Almost all the patients had altered sensorium or neurological deficit or a combination of both. All these patients were clinically assessed and grouped according to Glasgow Coma scale before the procedure was conducted.

\section{Preparation Of Patient:}

No preparation was required as only plain study was indicated in these patients

\section{Plan Of Study:}

Details were noted down on proforma either immediately before or after the procedure was carried out, depending on the status of the patient

\section{Equipment:}

Patients are scanned using single slice spiral: GE CT/e machine was used for the study which is a modified $5^{\text {th }}$ generation scanner.

Slice thickness used $: 1 \mathrm{~mm}, 2 \mathrm{~mm}, 5 \mathrm{~mm}, 10 \mathrm{~mm}$ and available gantry tilt: $+/-20$ degree

Matrix size of 512, Kv: 80-130 and Mas:60-200

\section{Ct Technique:}

Proper immobilisation and positioning of head was achieved in all patients. Unco-operative patients were sedated using I.V. Diazepam (5-20 mg). The gantry tilt was given in the range of +/-0-20 degrees, so as to parallel the scan plane to the orbito-meatal line. The obtained images were studied at brain and bone window settings. Average duration between scan and head injury was 6 to 8 hours. The patient was evaluated as per the proforma.

Surgical confirmation was obtained in 6 cases who were operated for elevation of depressed fracture fragment, craniotomy and evacuation of hematoma.

\section{Follow Up:}

Follow up of cases were performed in 3 cases who showed persistent neurological abnormality or deteriorated or failed to improve following surgical intervention

\section{Statistical Analysis:}

All the data were collected and converted into percentages wherever necessary. Chi square test and Spearman's correlation co-efficient were used for comparison of CT findings of different variables and parameters , $\mathrm{p}$ value was calculated using MINITAB (USA 13.1) programme.

\section{Results:}

In our study, 100 cases were included and analysed. The frequency distribution of various craniocerebral lesions in 100 patients has been summarised in table 1 .

The commonest parenchymal lesion was contusion apart from oedema. Fractures formed the next major group accounting for $81 \%$ of lesions. Linear fractures were detected in $64 \%$ patients while depressed fractures were noted in 12\% patients. Both linear and depressed fractures were seen in $5 \%$ (table 2).

About $45 \%$ of the patients were in $18-30$ years age group and $80 \%$ were males.

Isolated fractures were seen in 3 cases while 78 cases showed associated lesions. The commonest lesion was contusion which was seen in 40 cases and pneumocephalus accounted for 26 cases(table 3 ). Intracranial haemorrhage was seen in $8 \%$ cases and most commonly found in the frontal region. Haemorrhagic contusion was seen in $83.3 \%$ cases and non haemorrhagic in $16.6 \%$ cases (Table 4) Temporoparietal location and hyperdense density pattern was seen in predominance. Extradural haemorrhage was associated with overlying fracture in $93.75 \%$ cases (Table 5).

Outcome was poor with GCS score $<8$ while recovery was the rule with scores between $13-15 ; \mathrm{p}<0.01$ shows that the relationship is highly significant(Table 6). GCS was found to be inversely proportional to midline shift. $\mathrm{p}<0.01$ shows that the relationship is statistically significant. 
Outcome was poor in mass lesions and poorer in ICH and SDH as compared to EDH. $\mathrm{p}<0.001$ and $p<0.05$ respectively shows that relationship is significant (Table 7,8). Out of all the associated injuries, faciomaxillary injuries were seen most commonly in patients of head injury(Table 9).

Tables:

Table1: Frequency distribution of various craniocerebral lesions in 100 patients

\begin{tabular}{|l|l|l|}
\hline CT findings & Number of Patients & Percentage(\%) \\
\hline Fracture & 81 & 81 \\
\hline Pneumocephalus & 26 & 26 \\
\hline Extradural haemorrhage & 16 & 16 \\
\hline Subdural haemorrhage & 28 & 28 \\
\hline Intracerebral haemorrhage & 8 & 8 \\
\hline Intra ventricular haemorrhage & 4 & 4 \\
\hline Herniation & 17 & 17 \\
\hline Oedema & 49 & 49 \\
\hline Contusion & 48 & 48 \\
\hline Midline shift & 27 & 27 \\
\hline
\end{tabular}

Table 2: Types of fractures and their distribution

\begin{tabular}{|l|l|l|}
\hline Types of fractures & Number of patients & Percentage(\%) \\
\hline Linear & 64 & 64 \\
\hline Depressed & 12 & 12 \\
\hline Linear +Depressed & 5 & 5 \\
\hline
\end{tabular}

Table 3: Association of fractures with various lesions

\begin{tabular}{|l|l|}
\hline Fractures & Number of patients \\
\hline Isolated fracture & 3 \\
\hline Fracture associated with other lesions & 78 \\
\hline Pneumocephalus & 26 \\
\hline EDH & 15 \\
\hline Contusions & 40 \\
\hline SDH & 21 \\
\hline Intracerebral haemorrhage & 5 \\
\hline
\end{tabular}

Table 4: Contusions

\begin{tabular}{|l|l|l|}
\hline Contusions & Number & Percentage(\%) \\
\hline Non haemorrhagic & 8 & 16.66 \\
\hline Haemorrhagic & 40 & 83.3 \\
\hline Total & 48 & 100 \\
\hline
\end{tabular}

Table 5: Extradural haemorrhage: relationship with overlying fractures

\begin{tabular}{|l|l|l|}
\hline & Number of patients & Percentage(\%) \\
\hline EDH with fracture & 15 & 93.75 \\
\hline EDH without fracture & 1 & 6.25 \\
\hline Total & 16 & 100 \\
\hline
\end{tabular}

Table 6: Outcome on the basis of Glasgow Coma scale

\begin{tabular}{|l|l|l|l|}
\hline Glasgow coma scale & Number of cases & Death & Percentage(\%) \\
\hline$<8$ & 47 & 22 & 46.8 \\
\hline $9-12$ & 27 & 0 & 0 \\
\hline $13-15$ & 26 & 1 & 3.8 \\
\hline
\end{tabular}

Table 7: Outcome on the basis of type of lesion

\begin{tabular}{|l|l|l|l|}
\hline Type of lesion & Number of patients & Death & Death(\%) \\
\hline Mass lesions & 61 & 22 & 95.65 \\
\hline Non mass lesions & 39 & 1 & 4.34 \\
\hline Total abnormal scan & 100 & 23 & 100 \\
\hline
\end{tabular}

Table 8: Outcome in various hematomas

\begin{tabular}{|l|l|l|l|}
\hline Hematomas & Number of patients & Death & Death(\%) \\
\hline EDH & 16 & 2 & 12.5 \\
\hline SDH & 28 & 9 & 32.1 \\
\hline ICH & 8 & 5 & 62.5 \\
\hline
\end{tabular}


Table 9: Associated extra cranial injuries

\begin{tabular}{|l|l|}
\hline Associated injury & Number of patients \\
\hline Facio-maxillary & 22 \\
\hline Chest & 7 \\
\hline Chest +Extremity & 1 \\
\hline Extremities & 15 \\
\hline
\end{tabular}

Table 10: Incidence of head injury in different ages (Zimmerman and Bilaniuk)

\begin{tabular}{|l|l|}
\hline $0-2$ years & $9.08 \%$ \\
\hline $3-10$ years & $25 \%$ \\
\hline $11-17$ years & $15.03 \%$ \\
\hline $18-30$ years & $19 \%$ \\
\hline $31-50$ years & $15 \%$ \\
\hline
\end{tabular}
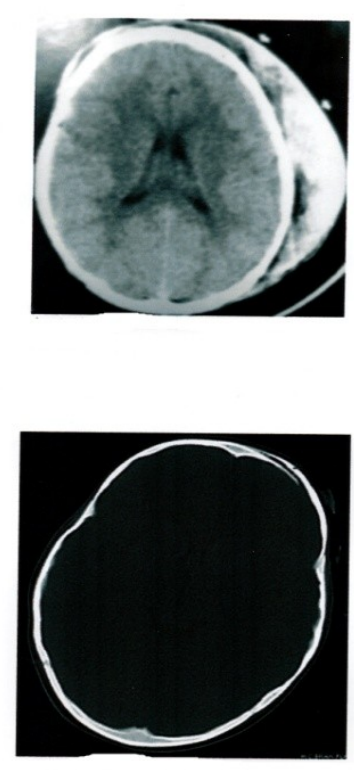

Axial NECT in a patient with trauma shows SUBGALEAL HEMATOMA (arrows) in the left parietal region and Axial NECT shows a linear fracture frontal bone on left side.
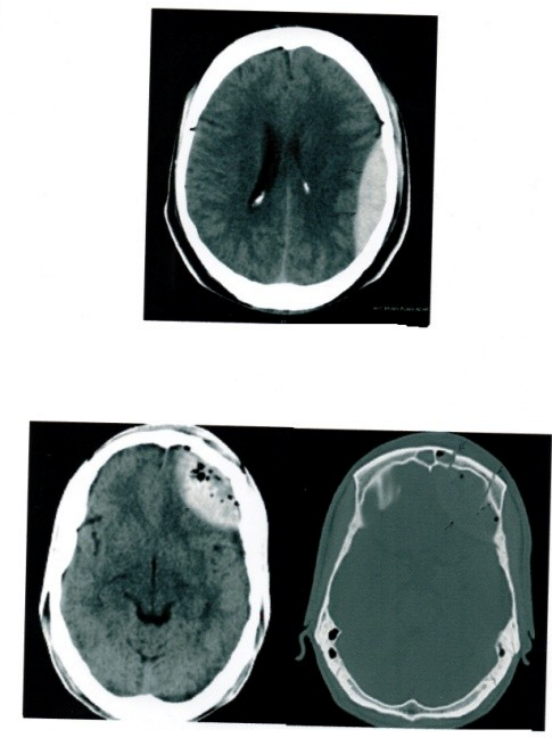

Axial NECT scan images shows ACUTE EXTRADURAL HEMATOMA (arrows) in the left parietal region and Axial NECT scan images shows EDH in the left frontal region with associated pneumocephalus and communited fracture of left frontal bone. 

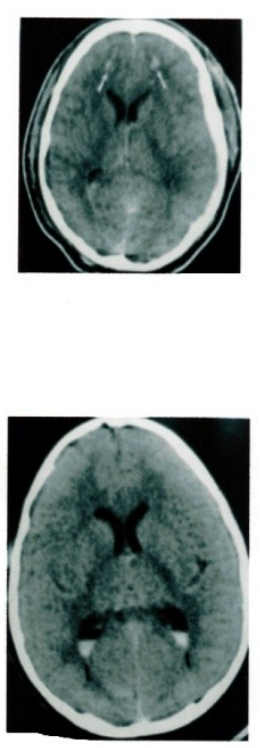

Axial NECT in a patient with trauma shows DIFFUSE AXONAL INJURY (bilateral frontal white matter hyperdensities (Arrows) with diffuse CEREBRAL EDEMA and axial NECT in a patient with trauma shows INTRAVENTRICULAR HAEMORRHAGE (hyperdense fluid levels in both the lateral ventricles).
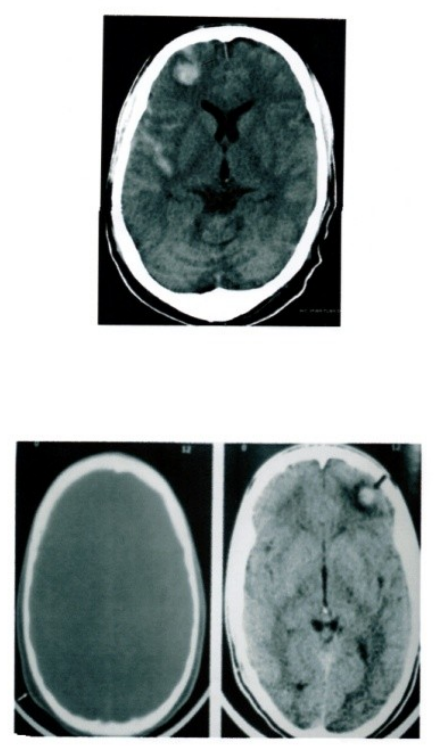

Axial NECT in a patient with trauma shows HAEMORRHAGIC CONTUSION (arrow) in the right frontal region with minimal SAH and axial NECT in a patient with trauma minimal soft tissue contusion in the right occipital region and CONTRECOUP injury in the left frontal region.

\section{Discussion:}

The present study includes 100 patients with the history of head trauma. CT findings of different lesions were then studied. The various CT appearances of traumatic lesions can be classified into early, late and secondary effects.

Early effects are acute cerebral swelling and brain oedema, contusions, fractures, pneumocephalus, extradural hematoma, subdural hematoma, intracerebral hematoma, intra ventricular haemorrhage, subarachnoid haemorrhage. Late effects are post traumatic hydrocephalus, focal atrophy and infection. Secondary effects are subfalcine, transtentorial or uncal herniation.

In the present study, we had $49 \%$ of patients with oedema which accounted for highest number of cerebral lesions. 
In the present study maximum head injuries occurred in age group of $19-50$ years $(79 \%)$ and people above 50 years were $21 \%$. Zimmerman and Bilaniuk ${ }^{1}$ reported the following incidence in 1978(Table 10).

In the present study, male to female ratio in our series of 100 patients was 9:1. Study by Clifton et al reported a similar ratio of $5: 1^{2}$.

In the present study, in case of mass lesions, $12.5 \%$ of EDH, $32.1 \%$ of SDH and $62.5 \%$ of ICH showed a fatal outcome. The outcome is therefore poor in SDH and ICH as compared to EDH, findings are correlated with those of Miller et al ${ }^{3}$.

In the present study, 27 patients had midline shift .Outcome was poor in patients with shift of more than $5 \mathrm{~mm}$ ( $45 \%$ mortality) while in patients with shift of $<5 \mathrm{~mm}$, outcome was good with recovery in all cases. This showed that GCS was inversely proportional to the midline shift.

In the present study, operative intervention was planned in 6 patients of which poor outcome was noted in one patient of SDH.

In our series of 100 patients, we had 8 cases of intracerebral hematoma. The most frequent site for traumatic ICH was noted to be the frontal lobe. This correlates with findings by KOO and Laroque ${ }^{4}$.

In the present study, out of $48 \%$ of contusions in our study, 8 cases $(16.66 \%)$ were non haemorrhagic while 40 cases $(83.33 \%)$ were haemorrhagic . Most had associated lesions. Associated intracranial hematoma, poor Glasgow coma scale and increasing age caused increased mortality in these patients ${ }^{5}$.

In the present study, we had 28 cases of SDH of which 24 showed the typical hyper dense pattern ${ }^{6.7} .21$ cases of SDH are associated with fracture. The findings correlated with the study done by Evans et al.

In the present study, we had 3 isolated fractures, 64 linear and 12 depressed fractures. 26 had accompanying pneumocephalus . CT detected fracture in $80 \%$ of the cases. Thus skull radiography have little or no role to play in modern day imaging in the presence of CT scan ${ }^{8,9}$.

\section{Conclusion:}

In our study of 100 patients with definite history of head trauma, we tried to evaluate the role of CT in these patients. A majority of the patients were males in their second and third decades of life. CT affected management where patient treatment can be decided upon by characterizing lesions based on type, size and associated midline shift.

CT along with clinical evaluation and Glasgow coma score helps in predicting the outcome of patients indicating its prognostic value; midline shift and age also play a major role.

Since only plain study is required, CT does not need patient preparation and because of its non invasive nature, speed and ease of use with other monitoring systems, it is the technique of choice for evaluating head injuries.

Thus , it is justifiable to conclude that this simple, inexpensive, highly effective and safe imaging modality should be considered the first imaging modality of choice in acute head injury as it forms cornerstone for rapid and effective diagnosis

\section{References:}

[1]. Zimmerman RA, Bilaniuk LT, Hackney DB, Goldberg HI. Head injury: Early results of comparing CT and high field MR. Amj Neuroradiology 1986; 147(6):1215-1222.

[2]. Clifton GL, Grossman RG, Makela ME, Miner ME. Neurological course and correlated computed tomography findings after severe closed head injury. J Neurosur 1980; 52(5):611-624.

[3]. Miller A, Ericson K. CT of isoattenuating subdural hematomas. Radiology 1979; 130(1):149-152.

[4]. Koo AH, Laroque RL. Evaluation of head trauma by computed tomography. Radiology 1977; 123 (2):345-350.

[5]. Jayakumar PN, Sastry Kolluri VR, Basavakumar DG. Prognosis in contrecoup intracranial hematomas. A clinical and radiological study of 63 patients. Acta Neurochir 1992; 108(1-2):30-33.

[6]. Evans RG. New frontier for radiology. Computed Tomography.40th Annual Preston M. Hickney Memorial lecture. Am J Roentgenol $1976 ; 126(6): 1117-1129$.

[7]. Lavender B, Stettin S, Svendsen P. Computer Tomography of traumatic intra and extracerebral lesions. Acta Radio 1975; 346: 107118 .

[8]. Feurman T, Wackym PA, Gade GF. Value of skull radiography, head computed tomographic scanning and admission for observation in case of minor head injury. Neurosurg 1988; 22(3): 449-453.

[9]. Hackney DB. Skull radiography in the evaluation of acute head trauma : a survey of current practice. Radiology 1991; 181(3):711714.

[10]. Udsteun GJ, Claar JM Imaging of acute head injury in the adult. Seminar in Ultrasound CT MR, 2001;22(2): $135-147$. 